\title{
Comparative chromosome studies in species of subtribe Orchidinae (Orchidaceae)
}

\author{
Alessio Turco', Antonella Albano', Pietro Medagli', \\ Robert P. Wagensommer², Saverio D'Emerico ${ }^{3}$
}

I Dept. of Biological and Environmental Sciences and Technologies, University of Salento, Strada Provinciale Lecce-Monteroni, 73100 Lecce, Italy 2 Dept. of Biology, Via E. Orabona 4, "Aldo Moro" University of Bari, 70125 Bari, Italy 3 "Aldo Moro" University of Bari, 70125 Bari, Italy

Corresponding author: Robert P. Wagensommer (robert.wagensommer@uniba.it)

Academic editor:ViktoriaShneyer| Received 1 October 2021|Accepted22November2021|Published 17December 2021

http://zoobank.org/9217943B-7061-4819-8FE4-COC6112E8D2F

Citation: Turco A, Albano A, Medagli P, Wagensommer RP, D’Emerico S (2021) Comparative chromosome studies in species of subtribe Orchidinae (Orchidaceae). CompCytogen 15(4): 507-525. https://doi.org/10.3897/compcytogen. v15.i4.75990

\begin{abstract}
In our study, FISH mapping using 18S-5.8S-25S rDNA and 5S rDNA sequences was performed for the first time on Ophrys tenthredinifera Willdenow, 1805, Serapias vomeracea (Burman f., 1770) Briquet, 1910 and Himantoglossum hircinum (Linnaeus, 1753) Sprengel, 1826. A detailed study was also performed on O. tenthredinifera using Giemsa-staining, silver-staining, CMA fluorescence banding and fluorescence in situ hybridisation (FISH) with rDNA probes. We analysed two subspecies, i.e. O. tenthredinifera subsp. neglecta (Parlatore, 1860) E.G. Camus, 1908 and O. tenthredinifera subsp. grandiflora (Tenore, 1819) Kreutz, 2004 by the traditional Feulgen method and constructed the karyotype. The cytotaxonomic implications for both taxa are also discussed. In Himantoglossum hircinum, FISH and silver staining highlighted differences in the number of two rDNA families (35S and 5S) with respect to Barlia robertiana (Loiseleur-Deslongchamps, 1807) Greuter, 1967. In addition, fluorescence in situ hybridisation was also applied to diploid $(2 n=2 x=36)$ and triploid $(2 n=3 x=54)$ Anacamptis morio (Linnaeus, 1753) R.M. Bateman, Pridgeon et M.W. Chase, 1997. As far as we are aware, this is the first case of autotriploidy observed in A. morio.
\end{abstract}

\section{Keywords}

Anacamptis, C-banding, Cytotaxonomy, FISH, Himantoglossum, Karyotype, Ophrys, Serapias

Copyright Alessio Turco et al. This is an open access article distributed under the terms of the Creative Commons Attribution License (CC BY 4.0), which permits unrestricted use, distribution, and reproduction in any medium, provided the original author and source are credited. 


\section{Introduction}

Over the years, various karyological aspects including ploidy level, total length of the chromosome set, symmetry indices and amount of nuclear DNA (Siljak-Yakovlev and Peruzzi 2012) have proved to be useful tools for studying cytotaxonomy and for understanding chromosome evolution (Stace 2000; Guerra 2012; Ilnicki 2014; Sharma and Mukai 2015), as have other studies of structural variation looking at chromosomal features (e.g. secondary constrictions, AgNors and rDNA sites). In this context, these studies help to elucidate phylogenetic relationships between taxa. For example, analysis of differences in karyotype asymmetry have been shown to be good indicators of chromosomal diversification in terms of size and morphology within a group (Levitsky 1931; Stebbins 1971; Peruzzi and Eroğlu 2013; Astuti et al. 2017).

These cytogenetic studies have also played an important role in describing the main features in the systematics and phylogeny of orchids, based on both chromosomal analysis by traditional techniques (D'Emerico 2001 and references therein) and analyses of the structural variation of chromosomes (e.g. Giemsa C-banding, FISH, etc.) (Schwarzacher and Schweizer 1982; D’Emerico et al. 1999; D’Emerico et al. 2001; Moscone et al. 2007; Lan and Albert 2011).

The subtribe Orchidinae Vermeulen, 1977 comprises about 35 genera of mostly terrestrial orchids (Pridgeon et al. 2001), 15 of which occur in Italy (GIROS 2016; Bartolucci et al. 2018; Martellos et al. 2020). In this context, Ophrys Linnaeus, 1753 is probably the richest in species, many of which are endemic to restricted areas and are more or less threatened with extinction (Wagensommer et al. 2020; Turco et al. 2021). From a cytogenetic point of view, the chromosome numbers of at least 23 of these genera have been investigated by various researchers (D'Emerico 2001 and references therein). On the other hand, detailed investigations of the morphology of $\mathrm{Or}$ chidinae chromosomes have only been performed on the genera Anacamptis Richard, 1817, Chamorchis Richard, 1817, Dactylorhiza Necker ex Nevski, 1935, Himantoglossum Sprengel, 1826, Neotinea Reichenbach f., 1852, Ophrys Linnaeus, 1753, Orchis Linnaeus, 1753, Platanthera Richard, 1817, and Serapias Linnaeus, 1753 (D'Emerico 2005). Comparison of plant karyotypes using conventional cytological techniques can contribute to taxonomy and can provide insight into genome organisation and evolution in various genera (Turco et al. 2018).

The first systematic study of the karyomorphology of Orchidinae in Europe was undertaken by Bianco et al. $(1988,1989)$, who described the karyotypes of six different Ophrys species. In cytogenetic studies, in addition to the study of morphological chromosome features by traditional techniques, banding techniques with Giemsa and fluorochromes have also been used. These techniques have revealed variations in heterochromatin content in the chromosomal complements of some groups of Orchidinae (D'Emerico et al. 1996, 2000; D’Emerico et al. 2002a, 2002b; Pellegrino et al. 2000; D'Emerico et al. 2005; Baumann et al. 2012; Turco et al. 2020).

Molecular cytogenetic techniques such as fluorescence in situ hybridisation (FISH), used to identify repetitive sequence families and their distribution in plant chromo- 
somes, have proven to be powerful tools for characterising chromosomes and investigating taxonomic relationships in plant groups (Maluszynska and Heslop-Harrison 1993a, 1993b; Galasso et al. 1995, 1997; Zoldos et al. 1999). D’Emerico et al. (2001) reported the physical distribution of $18 \mathrm{~S}-5.8 \mathrm{~S}-25 \mathrm{~S}$ and $5 \mathrm{~S} \mathrm{rDNA}$ sequences in the chromosomes of five Orchidinae taxa for the first time.

Seeking to increase our knowledge and acquire data on the karyology and systematics of Orchidinae, we used FISH and other techniques to study the karyotypes and heterochromatin distribution of Ophrys tenthredinifera s.l. and three other Orchidinae, i.e. Himantoglossum hircinum (Linnaeus, 1753) Sprengel, 1826, Serapias vomeracea (Burman f., 1770) Briquet, 1910 and Anacamptis morio (Linnaeus, 1753) R.M. Bateman, Pridgeon et M.W. Chase, 1997, specifically their distribution of 18S-5.8S-25S and $5 \mathrm{~S}$ rDNA loci, in order to elucidate their importance in the plants' systematics and evolution.

\section{Methods}

The taxa examined and their collection sites are shown in Table 1. Mitotic chromosomes were observed in tissues of immature ovaries. A total of fifteen individuals of Ophrys tenthredinifera Willdenow, 1805 and five Himantoglossum hircinum were first analysed by Feulgen and C-banding methods. For these two species, at least ten metaphases were examined and the karyotype was constructed from well-spread metaphase plates. Four well-spread metaphase plates were then examined with the FISH technique. In addition, four specimens of Anacamptis morio and four of Serapias vomeracea were analysed by the FISH technique and five metaphase plates were selected.

Immature ovary tissues were pre-treated with $0.3 \%$ colchicine at room temperature for $2 \mathrm{~h}$. For Feulgen staining they were fixed for $5 \mathrm{~min}$ in 5:1:1:1 (v/v) absolute ethanol, chloroform, glacial acetic acid and formalin. Hydrolysis was performed at $20{ }^{\circ} \mathrm{C}$ in $5.5 \mathrm{~N} \mathrm{HCl}$ for $20 \mathrm{~min}$ (Battaglia 1957a, b). The material was then stained in freshly prepared Feulgen stain. For C-banding, immature ovaries were fixed in 3:1 ( $\mathrm{v} / \mathrm{v})$ ethanol-glacial acetic acid and stored in the deep-freeze for up to several months. Subsequently, they were squashed in $45 \%$ acetic acid; coverslips were removed by the dry ice method and the preparations air-dried overnight. Slides were then immersed in $0.2 \mathrm{~N} \mathrm{HCl}$ at $60{ }^{\circ} \mathrm{C}$ for $3 \mathrm{~min}$, thoroughly rinsed in distilled water and then treated

Table I. Specimens of taxa analysed in this study.

\begin{tabular}{lcc}
\hline \multicolumn{1}{c}{ Taxon } & Provenance & Collector \\
\hline $\begin{array}{l}\text { Ophrys tenthredinifera subsp. grandiflora } \\
\text { Ophrys tenthredinifera subsp. neglecta }\end{array}$ & Sicily, Francavilla di Sicilia (Messina); Niscemi (Caltanissetta) & Bartolo et Pulvirenti \\
& Apulia, Cassano Murge (Bari); Torre Canne (Brindisi), Gargano & D'Emerico et Medagli \\
Himantoglossum hircinum & promontory (Foggia) & \\
Serapias vomeracea & Apulia, Cassano Murge (Bari) & D'Emerico et Medagli \\
Anacamptis morio & Apulia, Adelfia (Bari) & D'Emerico \\
\hline
\end{tabular}


with $4 \% \mathrm{Ba}(\mathrm{OH}) 2$ at $20^{\circ} \mathrm{C}$ for $4 \mathrm{~min}$. After thorough rinsing they were incubated in $2 \times \mathrm{SSC}$ at $60^{\circ} \mathrm{C}$ for $1 \mathrm{~h}$. The stain used was 3-4\% Giemsa (BDH) at $\mathrm{pH} 7$.

For DAPI (4-6-diamidino-2-phenylindole) staining, ovaries were treated as for C-banding and stained using a buffered DAPI solution $(0.6 \mathrm{mg} / \mathrm{mL})$ for $5 \mathrm{~min}$. after which they were rinsed and mounted in 1:1 (v/v) buffer and glycerol. For chromomycin A3 (CMA) staining, slides were stained with $0.5 \mathrm{mg} / \mathrm{mL} \mathrm{CMA} \mathrm{for} 1 \mathrm{~h}$ and mounted in 1:1 (v/v) Mcllvaine's pH 7.0 buffer-glycerol. For identification of the nucleolus, AgNO3 precipitation was used (Lacadena and Cermeno 1985).

For Ophrys tenthredinifera Willd., 1805, chromosome measurements were performed using the freeware MicroMeasure 3.3 (http://www.colostate.edu/Depts/ Biology/MicroMeasure). Chromosome pairs were identified and arranged on the basis of length. The nomenclature used for describing karyotype composition followed Levan et al. (1964). Karyotype morphometric characters were evaluated by calculating the haploid complement, while the karyotype asymmetry indices $\mathrm{M}_{\mathrm{CA}}$ (Mean Centromeric Asymmetry) and $\mathrm{CV}_{\mathrm{CL}}$ (Coefficient of Variation of Chromosome Length) were used for the evaluation of karyotype asymmetry. Moreover, $\mathrm{CV}_{\mathrm{CI}}$ (Coefficient of Variation of the Centromeric Index) was used to evaluate heterogeneity in the position of the centromeres (Paszko 2006, Zuo and Yuan 2011, Peruzzi and Eroğlu 2013).

For fluorescence in situ hybridisation, the ribosomal sequences 18S-5.8S-25S (pTa71 - red signals) and 5S (pTa794 - green signals) were used as probes. Clone pTa71 was labelled with rhodamine-4-dUTP by nick translation, while pTa794 was labelled with digoxigenin-11-dUTP using polymerase chain reaction. The former contains a $9 \mathrm{~kb} E c o B l$ repeat unit of $18 \mathrm{~S}-5.8 \mathrm{~S}-25 \mathrm{~S}$ rDNA and intergenic spacer regions, isolated from Triticum aestivum Linnaeus, 1753 (Gerlach and Bedbrook 1979), and the latter corresponds to a complete 410 bp $5 \mathrm{~S}$ gene unit, containing the $5 \mathrm{~S}$ gene and intergenic spacer regions, isolated from Triticum aestivum (Gerlach and Dyer 1980). Pre-treatment of slides and the FISH procedure followed the protocol in Heslop-Harrison et al. (1991). The chromosomes and DNA probes were denatured together at $70{ }^{\circ} \mathrm{C}$ for $5 \mathrm{~min}$ and hybridisation was performed at $37^{\circ} \mathrm{C}$ overnight. After hybridisation, the coverslips were removed in $2 \times \mathrm{SSC}$ at room temperature and then washed thoroughly for $10 \mathrm{~min}$ in $20 \%(\mathrm{v} / \mathrm{v})$ formamide in $0.1 \times \mathrm{SSC}$ at $42{ }^{\circ} \mathrm{C}$ to remove sequences with less than $85 \%$ homology; the slides were then incubated in immunoflorescent reagents.

For detection of the digoxigenin-labelled probe, the slides were equilibrated in $4 \times \mathrm{SSC} / 0.1 \%(\mathrm{v} / \mathrm{v})$ Tween 20 and blocked in $5 \%(\mathrm{w} / \mathrm{v})$ bovine serum albumin in $4 \times$ SSC/0.1\% (v/v) Tween 20 for 5 min. Slides were incubated with sheep anti-digoxigenin antibody conjugated with FITC in a moist chamber at $37^{\circ} \mathrm{C}$ for $1 \mathrm{~h}$. The slides were washed in $4 \times \mathrm{SSC} /$ Tween $203 \times 5 \mathrm{~min}$ and subsequently counterstained with DAPI prior to observation. They were finally mounted in antifade solution AF1 (Citifluor) and examined with a Leitz epifluorescence microscope with single and triple band pass filters. The resulting images were processed with freeware image-editing software, applying the functions to the whole image. 


\section{Results}

The chromosomes of the studied species are shown in Figs 1-5. Unfortunately, in the analysed species it is rather difficult to obtain good metaphasic plates for FISH staining. Therefore, we considered only the visible signals with the pTa71 and pTa794 probes to document sites rich in GC and AT. The cytogenetic analysis showed the following characteristics.

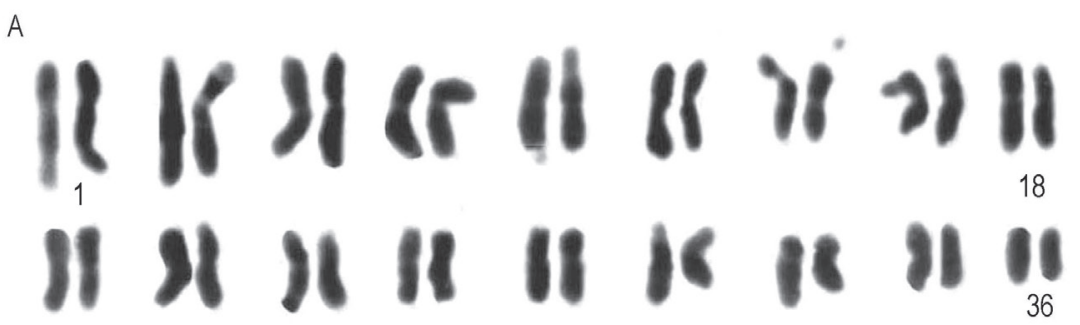

B

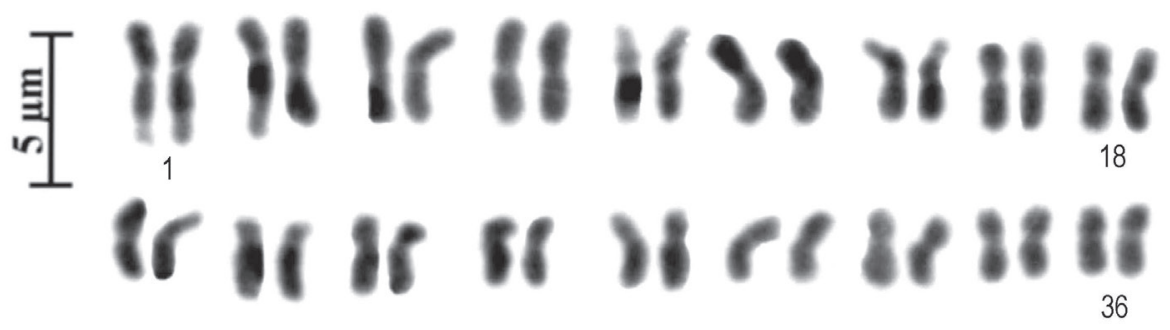

C

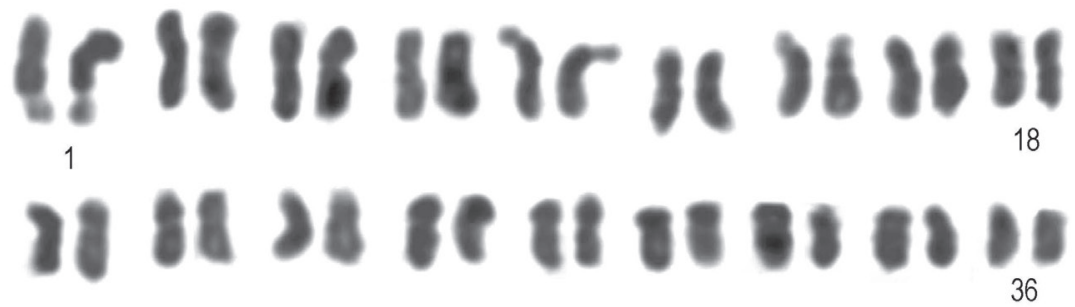

D

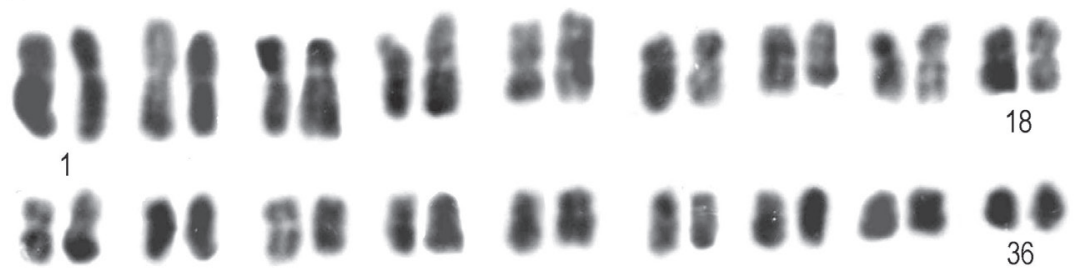

Figure I. A, B Diploid karyotype of Ophrys tenthredinifera subsp neglecta C diploid karyotype of $O$. tenthredinifera subsp. grandiflora D diploid karyotype of Himantoglossum hircinum. 
Table 2. Taxon, chromosome number, formula and morphometric parameters (mean \pm SE) in Ophrys tenthredinifera. MCA (Mean Centromeric Asymmetry), CVCL (Coefficient of Variation of Chromosome Length), CVCI (Coefficient of Variation of Centromeric Index). Chromosome abbreviations: m, metacentric; sm, submetacentric.

\begin{tabular}{lcccccc}
\hline \multicolumn{1}{c}{ Taxon } & $\begin{array}{c}\text { Number of } \\
\text { individuals }\end{array}$ & $\begin{array}{c}\text { Chromosome } \\
\text { number (2n) }\end{array}$ & Formula & $\mathbf{M}_{\mathrm{CA}}$ & $\mathbf{C V}_{\mathrm{CL}}$ & $\mathbf{C V}_{\mathrm{CI}}$ \\
\hline $\begin{array}{l}\text { Ophrys tenthredinifera subsp. } \\
\text { grandiflora }\end{array}$ & 5 & 36 & $32 \mathrm{~m}+4 \mathrm{sm}$ & $12.44 \pm 2.59$ & $16.83 \pm 0.84$ & $8.43 \pm 1.41$ \\
\begin{tabular}{l} 
O. tenthredinifera subsp. neglecta \\
\hline
\end{tabular} & 10 & 36 & $32 \mathrm{~m}+4 \mathrm{sm}$ & $13.29 \pm 0.11$ & $16.56 \pm 0.88$ & $10.80 \pm 0.79$ \\
\hline
\end{tabular}

Genus Ophrys: Mitotic metaphases in Ophrys tenthredinifera showed the chromosome number $2 n=2 x=36$. We analysed two subspecies of $O$. tenthredinifera, $O$. tenthredinifera subsp. neglecta (Parlatore, 1860) E.G. Camus, 1908 and O. tenthredinifera subsp. grandiflora (Tenore, 1819) Kreutz, 2004, with the traditional Feulgen method and composed the karyotype. The results are shown in Table 2 . The karyotypes of both subspecies were similar in terms of both the satellite pairs and the asymmetry indices. It is possible to observe four pairs of chromosomes, each with a satellite on the short arm (Figs 1A, B, C). The karyological formula shows 32 metacentrics plus 4 submetacentrics in both subspecies. The karyotype is the most symmetrical, having a low intrachromosomal asymmetry $\left(\mathrm{M}_{\mathrm{CA}}\right)$ index $(12.44-13.29)$ and a low interchromosomal asymmetry $\left(\mathrm{CV}_{\mathrm{CL}}\right)$ index $(16.56-16.83)$.

In $O$. tenthredinifera, C-banding showed the presence of centromeric heterochromatin, with a pair of chromosomes with a telomeric band. A large number of chromocentres were observed in interphase nuclei (Fig. 2A, B). The nucleolus organiser regions (NORs) revealed by $\mathrm{Ag}$-NOR staining were located in the telomeric region of the third chromosome pair (Fig. 2D), evidence that the six rDNA sites were active. However, in interphase nuclei it was possible to count up to three nucleoli (Fig. 2C). Moreover, in O. tenthredinifera, CMA staining revealed a positive signal on the NOR-bearing pair only (Fig. 2E). FISH analyses with the pTa71 (18S-5.8S25S) probe showed three signals (Fig. 4B), as revealed by the Ag-NOR staining in interphase nuclei (Fig. 2C). In addition, this species showed two pairs of $5 \mathrm{~S}$ rDNA sites (Fig. 4C).

Genus Serapias: Mitotic metaphases in Serapias vomeracea had $2 n=2 x=36$ chromosomes. In situ hybridisation shows that there are three pairs of 18S-5.8S-25S rDNA sites (Fig. 4E). The $5 \mathrm{~S}$ rDNA sequence was present on two pairs of chromosomes (Fig. 4F).

Genus Himantoglossum: All specimens of Himantoglossum hircinum had $2 n=2 x=$ 36 chromosomes. The $H$. hircinum karyotype consists of $28 \mathrm{~m}+8 \mathrm{sm}$. In $H$. hircinum a secondary constriction was seen in the short arm of pairs 4, 5 and 7 (Fig. 1D). Cbanding revealed that some chromosomes in $H$. hircinum possess small amounts of centromeric and telomeric constitutive heterochromatin (Fig. 3A). In interphase nuclei it was possible to count up to four nucleoli (Fig. 3B). Moreover, FISH revealed the location of four 18S-5.8S-25S rDNA sites (Fig. 4H) and four $5 \mathrm{~S}$ rDNA sites (Fig. 4I). 
Genus Anacamptis: In diploid Anacamptis morio $(2 n=2 x=36)$, silver nitrate staining in interphase nuclei counted up to four nucleoli. In this study, in situ hybridisation revealed the location of six 18S-5.8S-25S rDNA sites (Fig. 5A) and two $5 \mathrm{~S}$ rDNA sites (Fig. 5B). Fluorescence in situ hybridisation in triploids $(2 n=3 x=54)$ revealed nine 18S-5.8S-25S rDNA sites (Fig. 5D) and three 5S rDNA sites (5E).

A

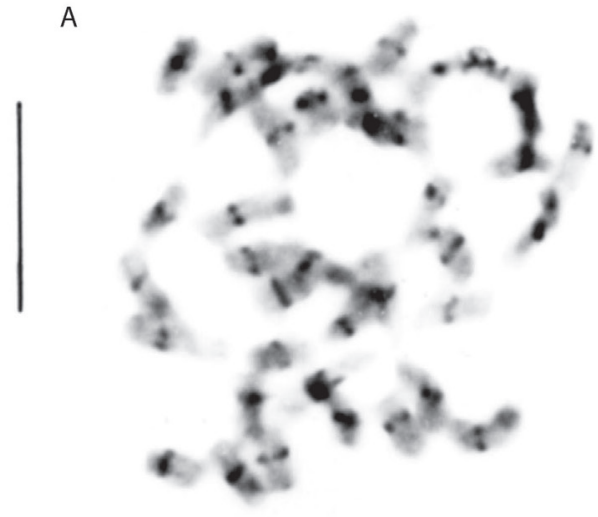

C
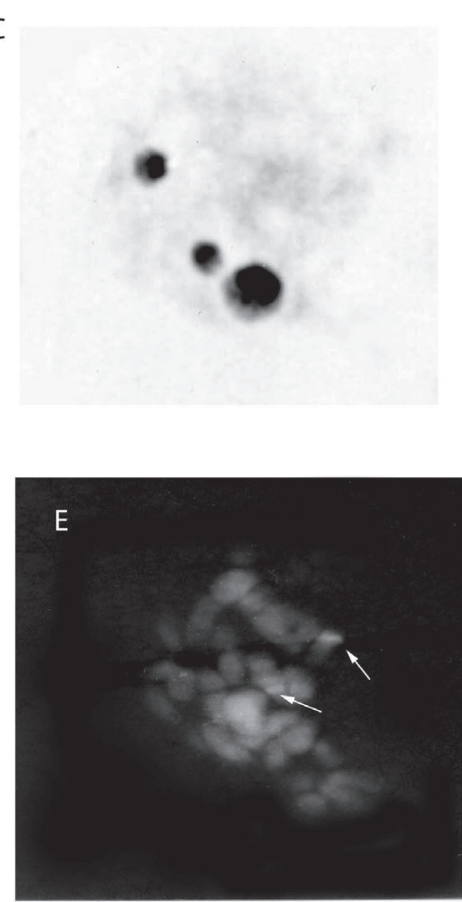

B

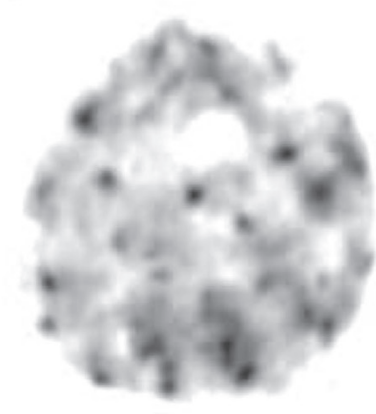

D

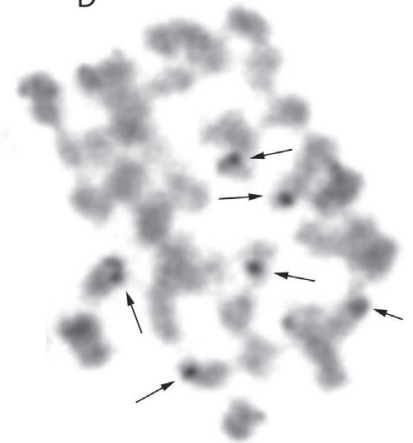

Figure 2. Ophrys tenthredinifera A Giemsa C-banding metaphase plate B Giemsa C-banding, interphase nucleus $\mathbf{C}$ silver staining, interphase nucleus $\mathbf{D}$ silver staining, mitotic metaphase $\mathbf{E}$ CMA staining, mitotic metaphase. Arrows indicate NOR sites. Scale bar: $5 \mu \mathrm{m}$. 
A

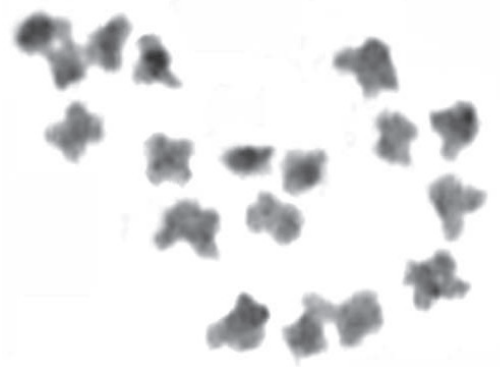

B

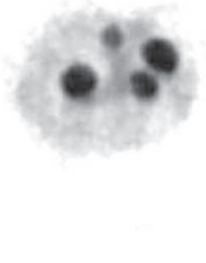

Figure 3. Himantoglossum hircinum A Giemsa C-banding, haploid metaphase $n=18$ B silver staining, interphase nucleus.
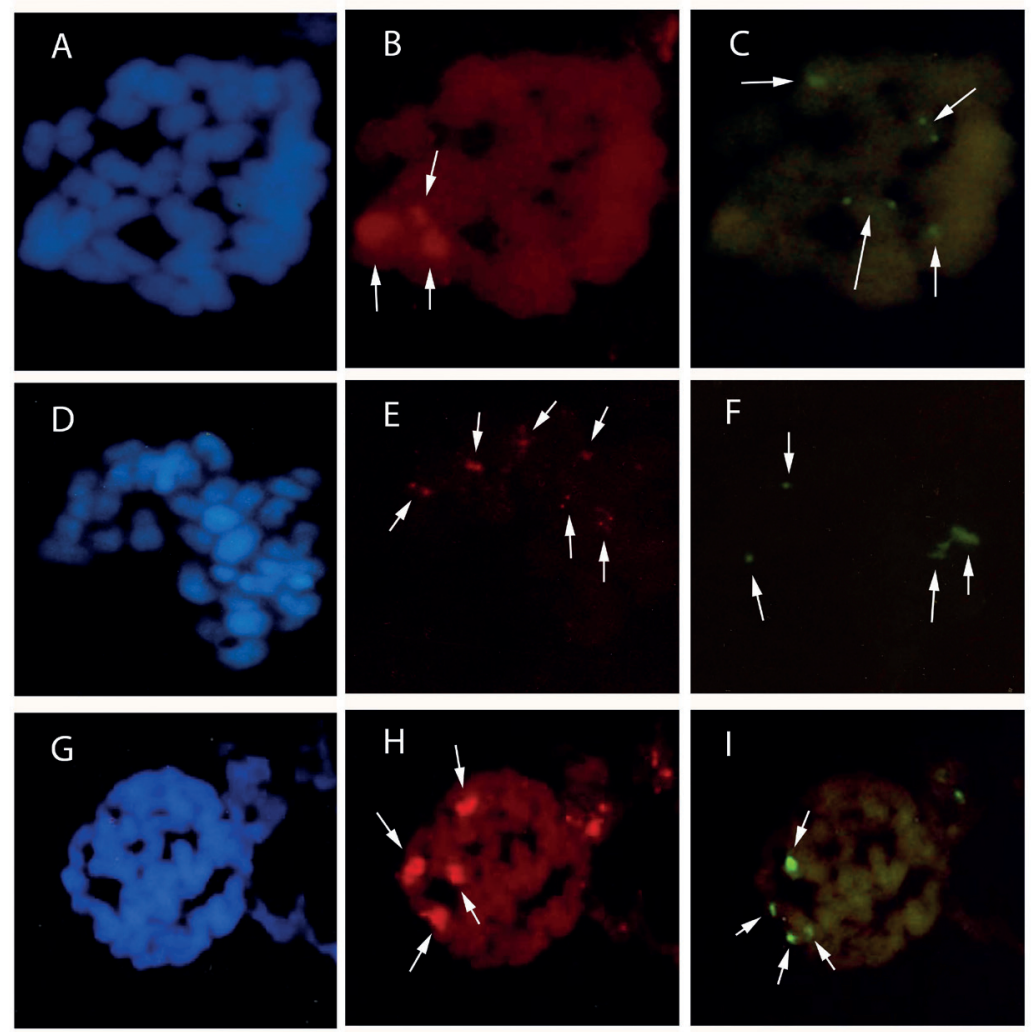

Figure 4. In situ hybridisation applied to chromosomes of orchid species. Blue DAPI staining shows chromosomal DNA (A, D, G, respectively Ophrys tenthredinifera, Serapias vomeracea and Himantoglossum hircinum); red and green signals show sites of hybridisation of 18S-25S rDNA and 5S rDNA respectively (B, E, H, C, F, I). Arrows indicate sites. Ophrys tenthredinifera (B) three 18S-25S rDNA sites and (C) four $5 \mathrm{~S}$ rDNA sites. Serapias vomeracea $(\mathbf{E})$ six $18 \mathrm{~S}-25 \mathrm{~S}$ rDNA sites and (F) four $5 \mathrm{~S}$ rDNA sites. Himantoglossum hircinum $(\mathbf{H})$ four 18S-25S rDNA sites and (I) four 5 S rDNA sites. 

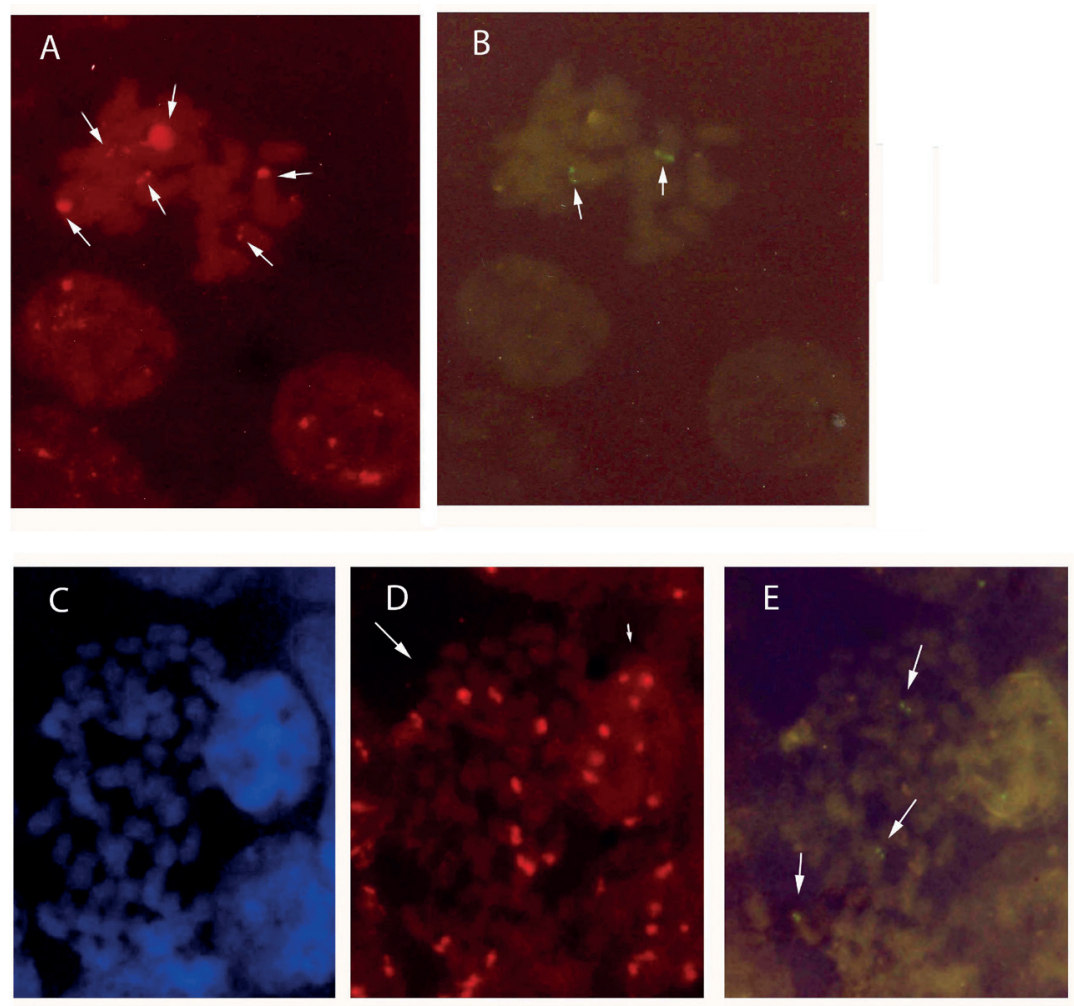

Figure 5. In situ hybridisation applied to chromosomes of Anacamptis morio. Blue DAPI staining shows chromosomal DNA $(\mathbf{C})$; red and green signals show sites of hybridisation of 18S-25S rDNA and $5 \mathrm{~S}$ rDNA respectively $(\mathbf{A}, \mathbf{D}, \mathbf{B}, \mathbf{E})$. Arrows indicate sites. Mitotic metaphase $2 n=2 x=36$ with $(\mathbf{A})$ six 18S-25S rDNA sites and (B) two 5S rDNA sites. Mitotic metaphase $2 n=3 x=54$ with (D) nine $18 \mathrm{~S}-25 \mathrm{~S}$ rDNA sites and (E) three 5S rDNA sites. Interestingly, a large number of 18S-5.8S-25S rDNA sites (9) were observed in interphase nuclei (small arrow).

\section{Discussion}

This paper reports the physical locations of rDNA loci on the somatic chromosomes of Ophrys tenthredinifera, Serapias vomeracea and Himantoglossum hircinum for the first time. Our analyses showed 18S-5.8S-25S rDNA sites and 5S rDNA sites in triploid specimens of Anacamptis morio.

The chromosome numbers, karyotype asymmetry and heterochromatin content of spontaneous populations of Ophrys tenthredinifera were determined. Mitotic metaphase plates showed $2 n=2 x=36$ chromosomes in all studied populations of $O$. tenthredinifera, which confirms the karyological stability of this taxon throughout its area of distribution (Scrugli 1977; Bianco et al. 1991; Bernardos et al. 2003; D'Emerico et al. 2005). Bernardos et al. (2003) reported $2 n=38+4 \mathrm{~B}$ and $2 n=38$ chromosomes for $O$. tenthredinifera in Iberia and North Africa respectively, while $2 n=3 x=$ 54 was reported by Bianco et al. (1991) in only one case. The first chromosome pair 
clearly shows a secondary constriction on the long arm, as observed in other works (D’Emerico et al. 2005; Deniz et al. 2017).

Regarding the infraspecific taxonomy of Ophrys tenthredinifera, this study analysed two subspecies, namely $O$. tenthredinifera subsp. neglecta, endemic to Sardinia and peninsular Italy from Tuscany to Calabria, and O. tenthredinifera subsp. grandiflora, endemic to Sicily and southern Calabria (GIROS 2016). The present study showed few intraspecific karyotype variations between populations of $O$. tenthredinifera subsp. neglecta and $O$. tenthredinifera subsp. grandiflora. These data do not therefore support a separation of these two taxa, as suggested in the World Checklist of selected Plant Families (WCSP), http://wcsp.science.kew.org/home.do, by Hennecke and Galano (2020).

Silver nitrate staining in interphase nuclei showed three nucleoli, although some meristematic cells had one large nucleolus. Moscone et al. (1995) suggest that the maximum number of nucleoli per nucleus generally coincides with the maximum number of NORs detected with silver nitrate. However, the number may be lower, due to frequent nucleoli fusions.

The 18S-5.8S-25S rRNA genes are normally located on the nucleolus organizing secondary constriction and adjacent heterochromatin, of which the nucleolar organiser region (NOR) is constituted. Whereas $5 \mathrm{~S}$ rDNA sites are exclusively detected by FISH, they do not form chromosome constrictions in metaphase chromosomes (Fuchs et al. 1998). In situ hybridisation shows that there are two pairs of 5S rDNA sites in Ophrys tenthredinifera. However, in O. tenthredinifera, the pTa794 signals were not intense.

The two subspecies $O$. tenthredinifera subsp. neglecta and $O$. tenthredinifera subsp. grandiflora may be affected by the epigenetic effects of heterochromatic sequences present on chromosomes. Indeed, Paun et al. (2010) analysed three sibling allotetraploid orchid species differing radically in terms of their geographical and ecological contexts, and showed that ecological divergence in Dactylorhiza species is mostly due to epigenetic factors regulating gene expression in response to environmental stimuli. Unfortunately, in the genus Ophrys, as far as we know, no study of this kind has been conducted.

Previous cytological studies in Serapias vomeracea have shown $2 n=2 x=36$ chromosomes (Heusser 1938; Del Prete 1977; Mazzola et al. 1981; Bianco et al. 1987). This species shows a moderately asymmetrical karyotype consisting of mainly submetacentric chromosomes (D’Emerico et al. 1992). Giemsa C-banding analysis showed conspicuous bands in centromeric positions on many chromosomes, together with euchromatic telomeric regions (D'Emerico et al. 2000). In Serapias vomeracea the 5 S rDNA signals on one pair were much more intense than those on the other pair. The presence of a major site of $5 \mathrm{~S}$ rDNA gene clusters could be regarded as further evidence of recent chromosomal restructuring (Abbo et al. 1994) of this species, reinforcing previous reports (D'Emerico et al. 2001 and references therein).

Serapias comprises about 25 species (Delforge 2016), and cytological studies have shown that most of them have $2 n=2 x=36$ chromosomes (D'Emerico et al 2000; Bernardos et al. 2004; Bellusci and Aquaro 2008). Polyploidy has been observed in $S$. lingua Linnaeus, 1753 (Brullo et al. 2014), S. olbia Verguin, 1908, S. gregaria Godfrey, 
1921 and S. strictiflora Welwitsch ex Veiga, 1887 (Bellusci and Aquaro 2008), all with $2 n=4 x=72$ chromosomes. The karyotype of numerous species of the genus Serapias has been observed using the Giemsa technique, with interesting results. Indeed, C-banded somatic metaphase plates showed broad centromeric bands on almost all chromosomes where heterochromatin occupies most of the chromosome, leaving a euchromatic segment in a telomeric position (D'Emerico et al. 2000). The karyology of Serapias lingua is interesting from the data obtained through conventional analyses alone, with numerous bivalents compared to the few tetravalents observed at metaphase I in EMC. Unfortunately, for this genus, the only data obtained with FISH in this study are reported for $S$. vomeracea.

Himantoglossum s.l. (including Comperia K. Koch, 1849 and Barlia Parlatore, 1860) is a group of species found in Portugal, Spain and across the Mediterranean region, including North Africa, the Aegean islands, Syria and Turkey, as well as the Crimea, the Caucasus and western and northern Iran (Wood 2001). The species Himantoglossum hircinum and $H$. adriaticum $\mathrm{H}$. Baumann, 1978 have a chromosome number of $2 n=$ $2 x=36$. Ströhlein and Sundermann (1972) reported $2 n=2 x=30$ in Himantoglossum comperianum (Steven, 1829) P. Delforge, 1999, and Bernardos et al. (2006) reported $2 n=2 x=36$ for Himantoglossum metlesicsianum (W.P. Teschner, 1982) P. Delforge, 1999. The chromosomal numbers of the other species of the genus such as $H$. formosum (Steven, 1813) K. Koch, 1849, H. calcaratum (Beck, 1887) Schlechter, 1927, H. caprinum Sprengel, 1826 and H. montis-tauri Kreutz et W. Lüders, 1997 (Bateman et al. 2017) are unknown. Cases of aneuploidy with $2 n=36+1 \mathrm{~B}$ are known in both $H$. hircinum and $H$. adriaticum (Capineri and Rossi 1987; D'Emerico et al. 1993).

It is interesting to note that the World Checklist of selected Plant Families (WCSP) reports Barlia robertiana (Loiseleur-Deslongchamps, 1807) Greuter, 1967 as a synonym for Himantoglossum robertianum (Loiseleur-Deslongchamps, 1807) P. Delforge, 1999. Furthermore, in the new classification based on morphological and molecular data (Sramkó et al. 2014), Bateman et al. (2017) place Barlia robertiana in the new subgenus Barlia (Parlatore, 1860) R.M. Bateman, Molnar et Sramkó, 2017 within the genus Himantoglossum.

Comparative investigations of Himantoglossum hircinum and Barlia robertiana show similar karyotype morphologies, with mainly metacentric chromosomes, low asymmetry and little constitutive heterochromatin. H. hircinum was found to have four nucleoli in interphase nuclei. Moreover, in situ hybridisation showed four 18S5.8S-25S rDNA sites and four 5S rDNA sites. In contrast, double-target in situ hybridisation in Barlia robertiana revealed one pair of chromosomes carrying both the pTa794 and pTa71 signals on opposite arms (D'Emerico et al. 2001). In addition, interphase nuclei in Barlia robertiana had two nucleoli.

Giemsa C-banding and FISH yielded few data for Himantoglossum hircinum and Barlia robertiana, while for $H$. adriaticum, on which only the conventional Feulgen method was used, only the karyotype was established. As already mentioned, the asymmetry indices and karyological formulas of Himantoglossum hircinum and Barlia robertiana are so similar that it is hard to clearly distinguish between them. Furthermore, we did not obtain important data with Giemsa C-banding; the few discriminating data are visible 
only with silver staining and FISH. Therefore, in the future it will be useful to continue with the above analyses in order to obtain clarification regarding the phylogenetic relationships between Barlia robertiana and the other species of the genus Himantoglossum.

In Anacamptis morio, the chromosome number $2 n=2 x=36$ is consistent with previous reports (D'Emerico et al. 1996 and references therein). The karyotype consists of $30 \mathrm{~m}+6 \mathrm{sm}$. This species possesses the most symmetrical karyotype, comprising mainly metacentric chromosomes. Three satellited chromosomes were visible. In our study, neither the chromosomes nor the interphase nuclei of this species showed any differential reaction when stained with Giemsa or DAPI. Fluorescence in situ hybridisation mapping in diploid Anacamptis morio showed six 18S-5.8S-25S rDNA sites and two $5 S$ rDNA sites. In contrast, in a previous paper, D'Emerico et al. (2001) reported four 18S-5.8S-25S rDNA sites and two 5S rDNA sites.

In this study we report analyses of a triploid individual of Anacamptis morio with chromosome number $2 n=3 x=54$ for the first time. The same count has been reported in specimens of $A$. coriophora (Linnaeus, 1753) R.M. Bateman, Pridgeon et M.W. Chase, 1997, A. laxiflora (Lamarck, 1779) R.M. Bateman, Pridgeon et M.W. Chase, 1997 and A. pyramidalis (Linnaeus, 1753) Richard, 1817 (D'Emerico et al. 1992, 1993; Pegoraro et al. 2016, 2019; Doro 2020). Fluorescence in situ hybridisation mapping in this triploid showed nine 18S-5.8S-25S rDNA sites and three $5 \mathrm{~S}$ rDNA sites.

\section{Conclusions}

Fluorescence in situ hybridisation may authentically substantiate the genome structure and distribution of repetitive DNA families. In this context, our results provide new data on the cytogenetic differences between four genera within the Orchidinae and investigations of other species are expected to yield further insight. Moreover, these data constitute basic knowledge for facilitating the study of taxonomic relationships in other species of this subtribe. Some examples are given below.

In relation to the triploid individuals observed in the genus Anacamptis s.l., it is possible to add some interesting notes about $A$. pyramidalis, useful for other species where polyploid individuals have been observed. The species $A$. pyramidalis has $2 n=2 x=36,54,72$ chromosomes (D'Emerico et al. 1992, 1993; Pegoraro et al. 2016, 2019). Recently the new species A. berica Doro, 2020 has been reported by Doro (2020), with $2 n=4 \mathrm{x}=72$ chromosomes. In both cases, polyploid species with $2 n=4 x=72$ are referred to as autotetraploid, although Bianco et al. (1991) reported 36 bivalents with occasional quadrivalents at metaphase I in EMC. Giemsa C-banding has not yielded good results, but it would be interesting to analyse these species with other banding methods and FISH.

Also interesting from the karyological point of view are the Neotinea s.l. group, with $2 n=2 x=42$ chromosomes, and the polyploid insular neoendemic $N$. commutata (Todaro, 1842) R.M. Bateman, 2003 with $2 n=4 x=84$ (Mazzola et. al. 1981). An interesting result for $N$. commutata was reported by Pavarese et al (2013), who showed 
42 bivalents at Metaphase I in EMC, hypothesising that the species arose from allopolyploidisation. In this case, no further data was obtained by the FISH method.

The Orchis s.s. group, with a chromosomal number of $2 n=2 x=42$, is characterised by small chromosomes and a fairly complex structure. Polyploidy has been observed in Orchis canariensis Lindley, 1835, O. olbiensis Reuter ex Grenier, 1860 and $O$. patens Desfontaines, 1799, with $2 n=4 x=84$ chromosomes (Pellegrino et al. 2000; Bernardos et al. 2002; Bernardos et al. 2006). The O. mascula (Linnaeus, 1753) Linnaeus, 1755 complex, which includes the species $O$. mascula, $O$. provincialis Balbis ex Lamarck et Candolle, 1806, O. pauciflora Tenore, 1811 and $O$. patens, is still undergoing taxonomic evaluation. Cytogenetic analyses using differential banding methods based on Giemsa and fluorochromes such as DAPI and CMA3 have revealed a remarkable affinity between these species. In O. mascula, C-banded somatic metaphase chromosomes show distinctive heterochromatin distribution. In ten chromosome pairs of the complement, heterochromatin occupies most of the chromosomes, with euchromatin occupying only the telomeric region, while eleven pairs were euchromatic, characterised by the presence of thin centromeric bands. After staining with fluorochrome DAPI, the chromosomes of this species showed blocks of heterochromatin in telomeric and subtelomeric regions (D'Emerico et al. 2002a). The results reveal that the species of the O. mascula s.l. complex are cytogenetically different from those belonging to the remaining species of Orchis s.s. These differences open up interesting avenues of investigation regarding the involvement of heterochromatin in the evolutionary processes of these species. The presence of these chromosomal structures needs to be studied further, through these and other techniques.

\section{Acknowledgements}

We thank Giuseppina Bartolo and Santa Pulvirenti for helping us with the collection of $O$. tenthredinifera subsp grandiflora. Domenico Pignone and Incoronata Galasso for technical analysis as part of the FISH experiments. The reviewers Lorenzo Peruzzi and Quanwen Dou for corrections and suggestions that helped us to improve the early version of the manuscript.

\section{References}

Abbo S, Miller TE, Reader SM, Dunford RP, IP King (1994) Detection of ribosomal DNA sites in lentil and chickpea by fluorescent in situ hybridisation. Genome 37: 713-716. https://doi.org/10.1139/g94-101

Astuti G, Roma-Marzio F, Peruzzi L (2017) Traditional karyomorphological studies: can they still provide a solid basis in plant systematics? Flora Mediterranea 27: 91-98 https://doi. org/10.7320/FlMedit27.091 
Bartolucci F, Peruzzi L, Galasso G, Albano A, Alessandrini A, Ardenghi NMG, Astuti G, Bacchetta G, Ballelli S, Banfi E, Barberis G, Bernardo L, Bouvet D, Bovio M, Cecchi L, Di Pietro R, Domina G, Fascetti S, Fenu G, Festi F, Foggi B, Gallo L, Gottschlich G, Gubellini L, Iamonico D, Iberite M, Jiménez-Mejías P, Lattanzi E, Marchetti D, Martinetto E, Masin RR, Medagli P, Passalacqua NG, Peccenini S, Pennesi R, Pierini B, Poldini L, Prosser F, Raimondo FM, Roma-Marzio F, Rosati L, Santangelo A, Scoppola A, Scortegagna S, Selvaggi A, Selvi F, Soldano A, Stinca A, Wagensommer RP, Wilhalm T, Conti F (2018) An updated checklist of the vascular flora native to Italy. Plant Biosystems 152(2): 179-303. https://doi.org/10.1080/11263504.2017.1419996

Bateman RM, Molnár AV, Sramkó G (2017) In situ morphometric survey elucidates the evolutionary systematics of the Eurasian Himantoglossum clade (Orchidaceae: Orchidinae). PeerJ 5: e2893. https://doi.org/10.7717/peerj.2893

Battaglia E (1957a) A new '5 minutes-fixation' using cold hydrolysis. Caryologia 9: 368-370. https://doi.org/10.1080/00087114.1957.10797602

Battaglia E (1957b) A simplified Feulgen method using cold hydrolysis. Caryologia 9: 372373. https://doi.org/10.1080/00087114.1957.10797604

Baumann H, D'Emerico S, Lorenz R, Pulvirenti S (2012) Supernumerary chromosomes and speciation processes in Dactylorhiza urvilleana subsp. phoenissa (Orchidaceae) from Lebanon. Journal Europäischer Orchideen 44(4): 811-824.

Bellusci F, Aquaro G (2008) Contribution to the cytotaxonomical knowledge of four species of Serapias L. (Orchidaceae). Caryologia 61(3): 294-299. https://doi.org/10.1080/00087 114.2008.10589641

Bernardos S, Amich F, Gallego F (2003) Karyological and taxonomic notes on Ophrys (Orchidoideae, Orchidaceae) from the Iberian Peninsula. Botanical Journal of the Linnean Society 142(4): 395-406. https://doi.org/10.1046/j.1095-8339.2003.00198.x

Bernardos S, Amich F, Gallego F, Crespí A L (2002) Contributions to the knowledge on the orchid flora of Northern Portugal. Journal Europäischer Orchideen 34: 35-50.

Bernardos S, García-Barriuso M, León-Arencibia MC, Reyes-Betancort A, González-González R, Padrón M, Amich F (2006) A cytotaxonomic study of three endemic orchids of the Canary Islands. Annales Botanici Fennici 43: 161-166.

Bernardos S, Tyteca D, Amich F (2004) Cytotaxonomic study of some taxa of the subtribe Orchidinae (Orchidoideae, Orchidaceae) from the Iberian Peninsula. Israel Journal of Plant Sciences 52: 161-170. https://doi.org/10.1560/YD43-0MFC-ANN9-PYN0

Bianco P, D'Emerico S, Medagli P, Ruggiero L (1989) Karyological studies of some taxa of the genus Ophrys (Orchidaceae) from Apulia (Italy). Caryologia 42: 57-63. https://doi.org/10 .1080/00087114.1989.10796953

Bianco P, D’Emerico S, Medagli P, Ruggiero L (1991) Polyploidy and aneuploidy in Ophrys, Orchis and Anacamptis (Orchidaceae). Plant Systematics and Evolution 178: 235-245. https://doi.org/10.1007/BF00937966

Bianco P, Medagli P, D’Emerico S, Ruggiero L (1987) Numeri cromosomici per la flora italiana: 1154. Informatore Botanico Italiano 19: 322-332.

Bianco P, Medagli P, D’Emerico S, Ruggiero L (1988) Nuovo rinvenimento di Ophrys $\times$ venusiana Baumann \& Künkele (O. tarentina Gölz \& Reinhard $\times$ O. tenthredinifera Willd.) e 
studio cariologico delle specie parentali. Webbia 42: 43-47. https://doi.org/10.1080/008 37792.1988.10670426

Brullo C, D'Emerico S, Pulvirenti S (2014) A cytological study of four Sicilian Serapias (Orchidaceae). Caryologia 67(3): 260-264. https://doi.org/10.1080/0144235X.2014.974354

Capineri R, Rossi W (1987) Numeri cromosomici per la flora italiana: 1130-1131. Informatore Botanico Italiano 19: 314-318.

D’Emerico S (2001) Orchideae, Cytogenetics. In: Pridgeon AM, Cribb PJ, Chase MC, Rasmussen FN (Eds) Genera Orchidacearum 2: Orchidoideae. Oxford, Oxford University Press, Part 1: 335.

D'Emerico S (2005) Cytogenetic diversity in Orchis s.l. and allied genera (Orchidinae, Orchidaceae). In: Sharma AK and Sharma A (Eds) Plant genome, biodiversity and evolution, phanerogams (Higher groups). Enfield (NH), Science, Inc., 1(Part B): 61-87.

D’Emerico S, Bianco P, Medagli P (1992) Karyological studies on Orchidaceae. Tribe Ophrydeae, subtribe Serapiadinae. Caryologia 45: 301-311. https://doi.org/10.1080/00087114.1 992.10797233

D’Emerico S, Bianco P, Medagli P (1993) Cytological and karyological studies on Orchidaceae. Caryologia 46: 309-319. https://doi.org/10.1080/00087114.1993.10797271

D’Emerico S, Cozzolino S, Pellegrino G, Pignone D, Scrugli A (2002a) Heterochromatin distribution in selected taxa of the 42-chromosome Orchis s.l. (Orchidaceae). Caryologia 55: 55-62. https://doi.org/10.1080/00087114.2002.10589258

D’Emerico S, Cozzolino S, Pellegrino G, Pignone D, Scrugli A (2002b) Karyotype structure, supernumerary chromosomes and heterochromatin distribution suggest a pathway of karyotype evolution in Dactylorhiza (Orchidaceae). Botanical Journal of the Linnean Society 138: 85-91. https://doi.org/10.1046/j.1095-8339.2002.00008.x

D'Emerico S, Galasso I, Pignone D, Scrugli A (2001) Localization of rDNA loci by Fluorescent In Situ Hybridization in some wild orchids from Italy (Orchidaceae). Caryologia 54(1): 31-36. https://doi.org/10.1080/00087114.2001.10589211

D’Emerico S, Grünanger P, Scrugli A, Pignone D (1999) Karyomorphological parameters and C-bands distribution suggest phyletic relationship within the subtribe Limodorinae Bentham (Orchidaceae). Plant Systematics and Evolution 217: 147-161. https://doi. org/10.1007/BF00984927

D’Emerico S, Pignone D, Bartolo G, Pulvirenti S, Terrasi C, Stuto S, Scrugli A (2005) Karyomorphology, heterochromatic patterns and evolution in the genus Ophrys (Orchidaceae). Botanical Journal of the Linnean Society 148: 87-99. https://doi.org/10.1111/j.10958339.2005.00393.x

D’Emerico S, Pignone D, Bianco P (1996) Karyomorphological analyses and heterochromatin characteristic disclose phyletic relationships among $2 n=32$ and $2 n=36$ species of Orchis (Orchidaceae). Plant Systematics and Evolution 200: 111-124. https://doi.org/10.1007/BF00984752

D'Emerico S, Pignone D, Scrugli A (2000) Giemsa C-banded karyotypes in Serapias L. (Orchidaceae). Botanical Journal of the Linnean Society 133: 485-492. https://doi. org/10.1111/j.1095-8339.2000.tb01591.x

Del Prete C (1977) Numeri cromosomici per la flora italiana: 358-365. Informatore Botanico Italiano 9: 135-140. 
Delforge P (2005) Orchids of Europe, North Africa and the Middle East. A \& C. Black Ltd, London. [ISBN 10: 071367525X ISBN 13: 9780713675252]

Deniz IG, Genç I, Yücel G, Sümbül H, Sezik E, Tuna M (2017) Karyomorphology and nuclear DNA content for sixteen Ophrys L. taxa from Turkey. Plant Biosystems 152: 711-719. https://doi.org/10.1080/11263504.2017.1327899

Doro D (2020) Anacamptis berica - Una nuova specie tetraploide del gruppo di Anacamptis pyramidalis. J. Eur. Orch. 52(2-4): 427-460.

Fuchs J, Strehl S, Brandes A, Scheizer D, Schubert I (1998) Molecular-cytogenetic characterization of the Vicia faba genome - Heterochromatin differentiation, replication and sequence localization. Chromosome Research 6: 219-230. https://doi. org/10.1023/A:1009215802737

Galasso I, Blanco A, Katsiotis A, Pignone D, Heslop-Harrison JS (1997) Genomic organization and phylogenetic relationships in the genus Dasypyrum analysed by Southern and in situ hybridization of total genomic and cloned DNA probes. Chromosoma 106: 53-61. https://doi.org/10.1007/s004120050224

Galasso I, Schmidt T, Pignone D, Heslop-Harrison JS (1995) The molecular cytogenetics of Vigna unguiculata (L.) Walp: the physical organization and characterization of $18 \mathrm{~s}-5.8 \mathrm{~s}-$ 25s rRNA genes, 5s rRNA genes, telomere-like sequences, and a family of centromeric ripetitive DNA sequences. Theoretical and Applied Genetics 91: 928-935. https://doi. org/10.1007/BF00223902

Gerlach WL, Bedbrook JR (1979) Cloning and characterization of ribosomal RNA genes from wheat and barley. Nucleic Acids Research 7: 1869-1885. https://doi.org/10.1093/nar/7.7.1869

Gerlach WL, Dyer TA (1980) Sequence organization of the repeating units in the nucleus of wheat which contain 5s rRNA genes. Nucleic Acids Research 8: 4851-4855. https://doi. org/10.1093/nar/8.21.4851

GIROS, editor (2016) Orchidee d'Italia. Guida alle orchidee spontanee. Cornaredo (MI), Il Castello Ed., 303 pp.

Guerra M (2012) Cytotaxonomy: The end of childhood. Plant Biosystems 146(3): 703-710. https://doi.org/10.1080/11263504.2012.717973

Hennecke M, Galano C (2020) Ophrys subgen. Bombyliflorae sect. Tenthrediniferae, a synopsis. GIROS Orchidee Spontanee d'Europa 63(2): 358-419.

Heslop-Harrison JS, Schwarzacher T, Anamtawat Jonsoon K, Leitch AR, Sffl M, Leitch IJ (1991) In situ hybridization with automated chromosome denaturation. Technique 3: 109-116.

Heusser C (1938) Chromosomenverhältnisse bei schweizerischen basitonen Orchideen. Berichte der Schweizerischen Botanischen Gesellschaft 48: 562-599.

Ilnicki T (2014) Plant biosystematics with the help of cytology and cytogenetics. Caryologia 67(3): 199-208. https://doi.org/10.1080/00087114.2014.931642

Lacadena JR, Cermeno MC (1985) Nucleolus organizer competition in Triticum aestivumAegilops umbellulata chromosome addition lines. Theoretical and Applied Genetics 71: 278-285. https://doi.org/10.1007/BF00252067

Lan T and Albert VA (2011) Dynamic distribution patterns of ribosomal DNA and chromosomal evolution in Paphiopedilum, a lady's slipper orchid. BMC Plant Biology 11: 126. https://doi.org/10.1186/1471-2229-11-126 
Levan A, Fredga K, Sandberg AA (1964) Nomenclature for centromeric position on chromosomes. Hereditas 52: 201-220. https://doi.org/10.1111/j.1601-5223.1964.tb01953.x

Levitsky GA (1931) The karyotype in systematics. Bull. Appl. Bot. Gen. Pl. Breed. 27: 220-240. Maluszynska J, Heslop-Harrison JS (1993a) Physical mapping of rDNA in Brassica species. Genome 36: 774-781. https://doi.org/10.1139/g93-102

Maluszynska J, Heslop-Harrison JS (1993b) Molecular cytogenetics of the genus Arabidopsis: in situ localization of rDNA sites, chromosome numbers and diversity in centromeric heterochromatin. Annals of Botany 71: 479-484. https://doi.org/10.1006/anbo.1993.1063

Martellos S, Bartolucci F, Conti F, Galasso G, Moro A, Pennesi R, Peruzzi L, Elena Pittao E, Nimi PL (2020) FlorItaly - the portal to the Flora of Italy. PhytoKeys 156: 55-71. https://doi. org/10.3897/phytokeys. 156.54023

Mazzola P, Crisafi F, Romano S (1981) Numeri cromosomici per la flora italiana: 850 Informatore Botanico Italiano 13: 182-188.

Moscone EA, Loidl J, Ehrendorfer F, Hunziker AT (1995) Analysis of active nucleolus organizing regions in Capsicum (Solanaceae) by silver staining. American Journal of Botany 82(2): 276-287. https://doi.org/10.1002/j.1537-2197.1995.tb11495.x

Moscone EA, Samuel R, Schwarzacher T, Schweizer D, Pedrosa-Harand A (2007) Complex rearrangements are involved in Cephalanthera (Orchidaceae) chromosome evolution. Chromosome Res 15: 931-943. https://doi.org/10.1007/s10577-007-1174-6

Paszko B (2006) A critical review and a new proposal of karyotype asymmetry indices. Plant Systematics and Evolution 258: 39-48. https://doi.org/10.1007/s00606-005-0389-2

Paun O, Bateman RM, Fay MF, Hedren M, Civeyrel L, MW Chase (2010) Stable epigenetic effects impact adaptation in allopolyploid orchids (Dactylorhiza: Orchidaceae) research article. Molecular Biology and Evolution 27: 2465-2473. https://doi.org/10.1093/molbev/msq150

Pavarese G, Tranchida-Lombardo V, Galesi R, D'Emerico S, Casotti R, Cristaudo A, and Cozzolino S (2013) When polyploidy and hybridization produce a fuzzy taxon: the complex origin of the insular neoendemic Neotinea commutata (Orchidaceae). Botanical Journal of the Linnean Society 173: 707-720. https://doi.org/10.1111/boj.12093

Pegoraro L, Cafasso D, Rinaldi R, Cozzolino S, Scopece G (2016) Habitat preference and flowering-time variation contribute to isolation between diploid and autotetraploid Anacamptis pyramidalis. Journal of Evolutionary Biology 29(10): 2070-2082. https://doi.org/10.1111/ jeb. 12930.

Pegoraro L, De Vos JM, Cozzolino S, Scopece G (2019) Shift in flowering time allows diploid and autotetraploid Anacamptis pyramidalis (Orchidaceae) to coexist by reducing competition for pollinators. Botanical Journal of the Linnean Society 191(2): 274-284. https://doi. org/10.1093/botlinnean/boz043

Pellegrino G, Cozzolino S, D'Emerico S, Grünanger P (2000) The taxonomic position of the controversial taxon Orchis clandestina (Orchidaceae): Karyomorphological and molecular analyses. Botanica Helvetica 110: 101-107. https://doi.org/10.5169/seals-73589

Peruzzi L, Eroğlu HE (2013) Karyotype asymmetry: again, how to measure and what to measure? Comparative Cytogenetics 7: 1-9. https://doi.org/10.3897/compcytogen.v7i1.4431

Pridgeon AM, Cribb PJ, Chase MW, Rasmussen FN (2001) Genera Orchidacearum, Orchidoideae (part 1), Vol. 2. Oxford, Oxford University Press, 464 pp. 
Schwarzacher T, Schweizer D (1982) Karyotype analysis and heterochromatin differentiation with Giemsa C-banding and fluorescent counterstaining in Cephalanthera (Orchidaceae). Plant Syst Evol 141: 91-113. https://doi.org/10.1007/BF00986411

Scrugli A (1977) Numeri cromosomici per la flora italiana: 124-125 Informatore Botanico Italiano 9: 119-125.

Sharma SK, Mukai Y (2015) Chromosome research in orchids: current status and future prospects with special emphasis from molecular and epigenetic perspective. The Nucleus 58: 173-184. https://doi.org/10.1007/s13237-015-0152-1

Siljak-Yakovlev S, Peruzzi L (2012) Cytogenetic characterization of endemics: past and future. Plant Biosystems 146: 694-702.

Sramkó G, Molnár V, Hawkins JA, Bateman RM (2014) Molecular phylogeny and evolutionary history of the Eurasiatic orchid genus Himantoglossum s.l. (Orchidaceae). Annals of Botany 114: 1609-1626. https://doi.org/10.1093/aob/mcu179

Stace C A (2000) Cytology and cytogenetics as a fundamental taxonomic resource for the $20^{\text {th }}$ and $21^{\text {st }}$ centuries. Taxon 49: 451-477. https://doi.org/10.2307/1224344

Stebbins (1971). Chromosomal evolution in higher plants. London.

Ströhlein H, Sundermann H (1972) Chromosomenzählungen bei Erdorchideen. Jahresbericht naturwisschaften Vereins Wuppertal 25: 75-80.

Turco A, Albano A, Medagli P, D'Emerico S (2020) Contribution to the study of wild Orchidaceae, genus Platanthera L.C.M. Richard. Karyotype and C-banding analysis of two species from Italy. Caryologia 73 (4): 11-16. https://doi.org/10.13128/Caryologia-811

Turco A, Albano A, Medagli P, Pulvirenti S, D’Emerico S (2018) New cytological data in Ophrys sect. Pseudophrys Godfery and comparative karyomorphological studies in Ophrys L. (Orchidaceae). Plant Biosystems 152(5): 901-910. https://doi.org/10.1080/11263504 .2017 .1362058

Turco A, Medagli P, Wagensommer RP, D’Emerico S, Gennaio R, Albano A (2021) A morphometric study on Ophrys sect. Pseudophrys in Apulia (Italy) and discovery of Ophrys japigiae sp. nov. (Orchidaceae). Plant Biosystems, online first. https://doi.org/10.1080/11263504 .2021 .1897702

Wagensommer RP, Medagli P, Turco A, Perrino EV (2020) IUCN Red List evaluation of the orchidaceae endemic to Apulia (Italy) and considerations on the application of the IUCN protocol to rare species. Nature Conservation Research 5(suppl. 1): 90-101. https://doi. org/10.24189/ncr.2020.033

Wood J (2001) Himantoglossum. In: Pridgeon AM, Cribb PJ, Chase MW, Rasmussen FN (Eds) Genera Orchidacearum, Vol. 2, part 1: Orchidoideae. New York, Oxford University Press, $309 \mathrm{pp}$.

Zoldos V, Papes D, Cerbah M, Panaud O, Besendorfer V, Siljak-Yakovlev S (1999) Molecular-cytogenetic studies of ribosomal genes and heterochromatin reveal conserved genome organization among 11 Quercus species. Theoretical and Applied Genetics 99: 969-977. https://doi.org/10.1007/s001220051404

Zuo L, Yuan Q (2011) The difference between the heterogeneity of the centromeric index and intrachromosomal asymmetry. Plant Systematics and Evolution 297: 141-145. https:// doi.org/10.1007/s00606-011-0528-x 


\section{ORCID}

Antonella Albano https://orcid.org/0000-0002-0874-320X

Alessio Turco https://orcid.org/0000-0001-9071-344X

Robert P. Wagensommer https://orcid.org/0000-0002-1614-4821 